\title{
O ACOLHIMENTO DE ESTUDANTES INTERNACIONAIS: BRASILEIROS E TIMORENSES EM PORTUGAL
}

\author{
The reception of international students: \\ Brazilians and Timorese in Portugal
}

\author{
Juliana Chatti lorio* \\ Silvia Garcia Nogueira**
}

\begin{abstract}
Resumo. Este artigo pretende analisar como Portugal tem acolhido os seus estudantes internacionais. Baseando-se em dois projetos de pesquisa relativos ao ensino superior português, irá apresentar um estudo comparativo entre o acolhimento que Portugal tem proporcionado aos oriundos do Brasil e do Timor-Leste, na ótica desses alunos. Ambas as investigações, através do recurso ao método de análise qualitativo (entrevistas realizadas a esses estudantes), chegaram a uma confluência de interpretações sobre o modo como estes estudantes vêm sendo recebidos nas universidades portuguesas. Além disso, enquanto uma pesquisa completou esta análise utilizando, também, um método quantitativo (aplicação de um questionário online), a outra utilizou o método etnográfico. Conclui-se que, neste aspecto, ainda há muito a ser feito, como uma maior atenção às dificuldades de brasileiros e timorenses com o Português de Portugal, mais sensibilização dos professores para com os estudantes provenientes de sistemas educacionais distintos, maior divulgação dos serviços disponíveis pelas universidades aos estrangeiros e apoio efetivo e afetivo na chegada ao país de destino.
\end{abstract}

Palavras-chave: mobilidade estudantil internacional; Brasil; Portugal; Timor-Leste; acolhimento.

Abstract. This article aims to analyze how Portugal has hosted its international students. Based on two ongoing research projects related to Portuguese higher education, it will present a comparative study between the reception that Portugal has provided to the natives of Brazil and Timor-Leste, from the point of view of these students. Both investigations, through the method of qualitative analysis (interviews conducted with these students), reached a confluence of interpretations about the way these students have been received in Portuguese universities. In addition, while a research completed this analysis using, also a quantitative method

Universidade de Lisboa. Lisboa, Portugal. E-mail: juioriobr@hotmail.com. Orcid: 0000-00033606-2492.

** Universidade Estadual da Paraíba. Campina Grande - PB, Brasil. E-mail: silvianogueira_ri@ yahoo.com.br. Orcid: 0000-0002-5757-7148. 
(application of an online questionnaire), the other used the ethnographic method. It is concluded that, in this regard, there is still much to be done, such as greater attention to the difficulties faced by Brazilians and Timorese with Portuguese language from Portugal, more teachers' awareness of students from different educational systems, greater dissemination of available services universities and effective and affective support upon arrival in the country of destination.

Keywords: international student mobility; Brazil; Portugal; Timor-Leste; hostess.

\section{Introdução}

A última década tem sido marcada por um crescimento notável no número de estudantes internacionais para Portugal, entre os quais destacam-se os provenientes do Brasil e de outros países integrantes da Comunidade de Países de Língua Portuguesa (CPLP), como Angola, Cabo Verde (Fonseca, Hortas, 2011) e, mais recentemente, o Timor-Leste. Os referenciais culturais e linguísticos da antiga metrópole, além das relações históricas, têm sido apontados como as principais motivações para este fenômeno (Salt, 1997).

Em uma perspectiva ampliada, um outro fato impulsionador para isso parece residir naquilo que Góis e Marques (2009) denominam de um "Lusophone migrationsystem", um sistema de migração de nível meso (relacional) entre países de língua portuguesa, que cruza e se comunica com outros macro-sistemas migratórios "identificados por Massey (o sistema norteamericano, o sistema da Europa Ocidental e o sistema sul-americano), bem como Sistema de Migração Africano" (p. 29, tradução livre).

No que se refere ao Brasil, sabe-se que desde o período colonial português acontece a mobilidade das elites para estudar na, então, metrópole. E aqui é importante que se diga que, apesar de no debate e nas políticas públicas o movimento de pessoas ser dicotomizado em "mobilidade" e "migração" sendo o primeiro termo conotado, positivamente, com expectativas de ganho para os indivíduos e estados, e o segundo, negativamente, com a necessidade de integração social, controle e manutenção da identidade nacional (Faist, 2013) -, ao considerarmos a definição das Nações Unidas (1998) na qual Videira (2013, p. 139) já se havia baseado, de que "a migração internacional de um indivíduo implica que este se mude do seu país de residência atual para outro, por um período entre três meses e um ano (migração de curta duração) ou superior a um ano (migração de longa duração)", podemos dizer que todo o indivíduo que sair do seu país de origem para estudar no exterior, e lá permanecer por um período de, pelo menos, 3 meses, deverá ser considerado um migrante.

Neste sentido, tendo em conta que, segundo a Organização para Cooperação e Desenvolvimento Econômico (OCDE, 2013), a definição de 
estudante internacional implica, necessariamente, um movimento entre dois países, e a de estudante estrangeiro que o mesmo não seja cidadão do país de destino, pode-se dizer que, no caso do Brasil, só poderemos falar numa migração estudantil de cidadãos, propriamente brasileiros, após a independência deste país, em 1822¹.

Portanto, visto que o Brasil foi um dos últimos países da América Latina a estabelecer as suas universidades (a primeira, fundada em 1920, foi a Universidade do Rio de Janeiro), e apenas com as reformas universitárias de 1968 é que iniciou a internacionalização das mesmas, é somente a partir da década de 1970 que se começa a notar uma maior migração de brasileiros. Esta migração abarcou vários perfis, incluindo aqueles que começaram a migrar em busca de uma maior qualificação (Marques, Góis, 2014).

De acordo com Mazza (2008), entre 1970 e 2000, tendo em vista a formação de quadros qualificados, o fomento à pesquisa e os investimentos em ciência e tecnologia no horizonte da circulação internacional, cerca de 16.000 brasileiros realizaram parte da sua formação em outros países, ainda que, segundo esta autora, sempre tenha existido uma hierarquia distintiva de lugares, sendo os Estados Unidos da América e alguns países da Europa a primeira escolha destes estudantes.

Contudo, a partir de meados da década de 2000 e até 2011, o Brasil viveu um período de forte expansão econômica - um pouco perturbado pela crise mundial de 2008, mas seguido de um crescimento, ainda que fraco, até 2014 (Peixoto et alii, 2016) -, que aliado aos programas governamentais de financiamento à mobilidade estudantil internacional contribuiu não só para o retorno de muitos dos brasileiros que viviam no exterior, mas também para o aumento da migração de brasileiros para fins de estudo. Deste modo, a criação do Programa de Mobilidade Científica, Ciência sem Fronteiras (CsF), por exemplo, proporcionou o fortalecimento dos laços entre o Brasil e os EUA, mas também com outros países que se encontravam no centro da economia global, como alguns da União Europeia (Spears, 2014). Desde a criação do CsF, em 2011, até abril de 2013, Portugal foi o país que mais estudante recebeu ao abrigo deste programa².

\footnotetext{
1 E aqui iremos utilizar o termo "migração" (sem o (i) para identificar o movimento de chegada, ou o (e) para referir o movimento de saída), uma vez que segundo a Organização Internacional para as Migrações - OIM (2009, p. 40), a migração refere-se ao "processo de atravessamento de uma fronteira internacional ou de um Estado. É um movimento populacional que compreende qualquer deslocação de pessoas, independentemente da extensão, da composição ou das causas". 2 De acordo com os dados divulgados pelo site do CsF, em 04/02/2013, em dezembro de 2012 Portugal havia sido o principal destino dos estudantes brasileiros de graduação (com 2.343 bolseiros). No total, este país tinha recebido 2.775 bolseiros, ficando somente atrás dos EUA (com 3.898). A partir de Abril de 2013, quando Portugal passou a não fazer mais parte do Edital deste programa, começou a se verificar uma queda na posição que até então este país havia ocupado.
} 
Devido à crise mundial referida anteriormente, que afetou Portugal a partir de 2008 implicando o retorno de muitos migrantes, mas também a migração de muitos jovens portugueses (Peixoto et alii, 2016), este país, bem como as suas Instituições de Ensino Superior (IES), começaram a investir mais na captação de estudantes internacionais, com especial atenção para os falantes de língua portuguesa (Fonseca, Esteves, lorio, 2015). Segundo a Direção Geral de Estatísticas da Educação e Ciência (DGEEC) de Portugal, no ano letivo 2008/20093 os brasileiros tornaram-se a maior comunidade de estudantes estrangeiros no ensino superior português (com 21,3\%), sendo que, em 2011, de acordo com a OCDE (2013, p. 314), 64\% desses alunos eram provenientes de países como Brasil, Angola, Cabo Verde, Guiné-Bissau, Moçambique, São Tomé e Príncipe ou Timor-Leste. Houve, portanto, um maior investimento de Portugal na relação com as suas ex-colônias. Assim, apesar de no ano letivo de 2016/2017 os brasileiros terem se mantido como a maior comunidade de estudantes estrangeiros em Portugal, com 12.245 alunos, os timorenses já contabilizavam 293 estudantes. Em 2017/2018, somente entre os estudantes estrangeiros inscritos em mobilidade de grau ${ }^{4}$, os brasileiros continuavam a ocupar a primeira posição, com 10.129 inscritos, mas os timorenses já ocupavam a 13ạ posição, com 316 (DGEEC).

No caso específico do Timor-Leste, Portugal fez parte de um processo turbulento de descolonização que contribuiu para a criação de condições políticas favoráveis a uma violenta ocupação indonésia a partir de 1975. De acordo com Mendes (2011, p. 126), a relação de Portugal com Timor-Leste foi marcada por um "dilema habitual entre equilibrar a ética internacional e salvaguardar os interesses nacionais". Assim, esse autor ressaltou que Portugal tentou "conciliar a necessidade de lidar com forças e atores internacionais" com uma "capacidade de manobra" - fortalecendo uma política externa mais assertiva - ao conseguir entrar na Comunidade Europeia em 1986, com a intenção de "melhorar o seu soft power num novo mundo globalizado" (2011, p. 125-126). Portanto, participou de ações de state building, destinando "uma enorme quantidade de dinheiro para a cooperação com Timor-Leste e as Nações Unidas" (USD\$ 655,21 entre 1999 e 2007), além de ter assinado vários acordos de assistência e cooperação nas áreas de "educação, governação e justiça" com este país (Mendes, 2011, p. 127).

\footnotetext{
3 Ano letivo refere-se ao período no qual são desenvolvidas as atividades escolares efetivas. Em Portugal este ano tem início em setembro e termina em junho do ano seguinte. Por isso um ano letivo é denominado por dois anos, por exemplo, 2008/2009.

4 Matriculados num estabelecimento de ensino superior português, que concluíram o ensino secundário num país estrangeiro e têm como finalidade a obtenção de um diploma (DGEEC Inscritos em mobilidade internacional no ano letivo 2013/2014 - Mobilidade de Grau).
} 
Timor-Leste, por sua vez, após ter recebido ajuda internacional (Silva, 2008), conseguiu sua independência em 2002, depois de 24 anos sob dominação indonésia, mais de 400 anos como colônia portuguesa, e um período aproximado de uma década sob intervenção da Organização das Nações Unidas (Durand, 2009). Frente tal trajetória, e no atual processo de state/nationbuilding (Leach, 2017), começou a investir na formação superior internacional de seus jovens, tendo no envio de estudantes para Portugal, seguindo orientações traçadas no Plano Estratégico de Desenvolvimento 2011-2030 (República Democrática do Timor-Leste - RDTL, 2011), uma estratégia para capacitar profissionais da sua administração pública ${ }^{5}$ com o domínio da língua portuguesa.

Portanto, diante do aumento de estudantes brasileiros e timorenses em Portugal, este artigo pretende discutir algumas questões pouco debatidas até então: (1) Como estes estudantes têm sido acolhidos por Portugal? (2) Será que Portugal está preparada para bem recebê-los? (3) A partilha do mesmo idioma tem facilitado este acolhimento?

Após uma breve revisão bibliográfica acerca da questão do acolhimento, e a exposição dos dados de ambos estudos, apresentaremos, de forma comparativa, os resultados obtidos, de onde se deverá tirar algumas ilações e recomendações futuras.

\section{A questão do acolhimento}

A partir dos anos 1970, as sociedades contemporâneas começaram a ser transformadas pela globalização neoliberal. Nelas, segundo Martinez (2017), ocorreu uma tentativa de homogeneizar os valores, os saberes e as culturas, tendo como base o eurocentrismo que continuou a subjugar outros conhecimentos e culturas. Paralela e paradoxalmente, conforme Guimarães e Finardi (2018, p. 17), a "multiplicidade de culturas, línguas e a mobilidade de pessoas têm-se tornado o foco de discussões políticas entre Estados", no sentido de empreender "esforços à elaboração de políticas de imigração, políticas linguísticas e políticas de internacionalização da educação superior" como é o caso da União Europeia.

No que diz respeito a Portugal, este país criou um "Plano para Integração de Imigrantes, que trata de temas como língua, cultura e comunicação, assim como formação para a interculturalidade" (Guimarães, Finardi, 2018, p. 17). Para essas autoras, o desafio para a diversidade cultural não se transformar

\footnotetext{
5 A língua portuguesa, ao lado do Tétum, é um dos idiomas oficiais do Timor-Leste, ainda que poucos sejam os timorenses que nela sejam versados. Este fenômeno é uma das consequências da política de educação em língua indonésia no período de ocupação do país, que afetou uma grande parte dos jovens educados nessa época e que hoje compõem a maioria da população timorense, cuja média de idade é de 17,4 anos (RDTL, 2011).
} 
em obstáculo às interações sociais é envolver questões referentes às relações interculturais, gestão da interculturalidade, gestão da comunicação, comunicação intercultural, negociação de identidades e resolução de conflitos (Ramos, 2013), fazendo da interculturalidade uma peça "chave". Particularmente no que se refere aos estudantes estrangeiros, Sousa (2016, p. 334) chama a atenção para "muitos desafios de convivência" - de mútuo relacionamento, envolvendo os que chegam e os pertencentes à sociedade que os acolhe - e da dificuldade prática de uma "educação intercultural que respeita o "Outro".

Apesar das singularidades inerentes aos países que foram antigas colônias portuguesas (como o Brasil e o Timor-Leste), os laços históricos, culturais e linguísticos continuam a assinalar as semelhanças com a ex-metrópole. Deste modo, as relações estabelecidas entre ex-colonizador e ex-colonizados passam a envolver as representações, o "espaço imaginado", que os últimos têm do primeiro, influenciando, inclusive, o desejo da migração e a expectativa do acolhimento.

O vínculo estabelecido entre os que acolhem e os que são acolhidos pode ser mais bem entendido se considerarmos a noção de hospitalidade e o que ela implica. Especificamente quanto à cooperação acadêmica, pode-se entender que tal noção é intrínseca, abrangendo a relação entre migrantes e Estados, além das interações sociais entre indivíduos com pertenças culturais distintas. Conforme Manzi e Toudoire-Surlapierre (2011, p. 795), a hospitalidade envolve ter que lidar com o estrangeiro, "ainda que a distância e a estranheza que Ihe são próprias possam ser variáveis". A interação entre hóspedes e anfitriões, em última instância, diz respeito a quem são e o que de si oferecem uns aos outros.

Receber bem os estudantes que chegam implica na "dádiva da hospitalidade" (Perrot, 2011; Nogueira, 2014), em que algo do doador é ofertado ao receptor e algo do receptor é retribuído para o doador, criando vínculos e pondo em questão a identidade de ambos: "aquele que dá (a hospitalidade) recebe (o outro), e aquele que é recebido (no caso do outro) Ihe dá de si mesmo. Dessa renúncia ao recolhimento identitário 'egoísta' nasce o sentimento de um comum pertencimento" (Perrot, 2011, p. 70).

Para Montandón (2011), praticar a hospitalidade é "fazer uma dádiva de si". Os laços criados pelas dádivas e contradádivas, como lembra Mauss (1966), são uma alternativa à guerra. Na situação de cooperação internacional é um jogo estratégico de explicitação daqueles que são os amigos e os inimigos (Nogueira, 2014). O desafio, segundo Binet-Montandon (2011, p. 1176), é que na dimensão relacional entre aquele que acolhe e o que é acolhido é necessário que se leve em consideração "o universo cultural do migrante e de seus códigos". 
Um outro aspecto da hospitalidade é o seu caráter ambíguo: aquele que entra em sua "casa" é visto como alguém de fora que, ao passar pela "soleira" da porta, é tratado como alguém de dentro, abrangendo uma oposição exterior/interior, inserção/exclusão, nomadismo/sedentarismo (Grassi, 2011). A ambiguidade também é ressaltada por Penchaszadeh (2017), para quem a hospitalidade e hostilidade se confundem, uma vez que há uma tensão na relação com o Outro. Esta tensão também é apontada por Perrot (2011), que entende que a dádiva da hospitalidade é uma mistura de acolhida, que pressupõe confiança, com "regras de boa conduta" (obrigações).

Assim, as representações sociais de anfitriões e hóspedes são elaboradas em meio a processos de práticas sociais, trocas e interações entre sujeitos que possuem interesses comuns, através do estabelecimento de redes sociais, mas também dos meios de comunicação social (Ferreira, Callou, 2016), que acabam por ser os elementos responsáveis pelo imaginário mobilizador da migração.

Pode-se dizer, portanto, que no imaginário de um "estudante-migrante" se pode formar a imagem de como será o acolhimento no país e na instituição de destino, a partir das informações que obtiveram antes de partir, e isto poderá movê-lo, ou não, para a ação de migrar. Quando um imaginário de aproximação com outro país é desenvolvido, o mesmo será colocado à prova no momento da chegada, assim que ocorrerem os primeiros contatos com o país de destino. É nesta fase que poderá emergir um quadro de "estranhamento" diante da realidade, face à representação que o, agora imigrante, tinha antes de emigrar (Ferreira, Callou, 2016, p. 13), uma vez que a vivência cotidiana poderá desconstruir o imaginário.

No caso de Portugal, e na visão de Castelo (1998, p. 13-14), a representação do eu português, ou do "modo português de estar no mundo" perdura na atualidade, num discurso político e cultural que tem acentuado a "imunidade" dos portugueses ao racismo, a sua pré-disposição para o convívio com outros povos e culturas, e a sua "vocação universalista". Esse discurso político e cultural tem influenciado a maneira como as antigas colônias imaginam as suas antigas metrópoles, já que "continua a existir uma ênfase representacional maior sobre o passado, do que sobre o presente ou o futuro" (Salazar, 2011, p. 581). Ou seja, se os países europeus pós-coloniais (como Portugal) continuam a perceber as suas ex-colônias (como Brasil e Timor-Leste) como se ainda fossem colônias (países subalternos), como irão receber os estudantes provenientes dessas antigas colônias?

Em primeiro lugar, é preciso, como já havia referido Cristina Bastos ${ }^{6}$ "ultrapassar ideologias monolíticas", como "a crença numa ausência de racismo,

6 Referido durante o "Encontro Ciência 2017", em Lisboa (Portugal), numa apresentação sobre "Trânsitos Atlânticos sem Caravelas ou Bússolas". 
ou num brando tratar das diferenças por parte daqueles que se exprimem em português, radicada numa hipotética capacidade de entrosamento dos colonizadores portugueses com os meios e povos tropicais". Contudo, de acordo com Waters (2012), uma vez no país de acolhimento, a tendência é o "estudante-migrante" mergulhar na cultura deste país, institucionalizando-a através das qualificações formais recebidas pela instituição de ensino que o acolheu e aceitando o acolhimento que the foi proporcionado, sem questionar. Como já havia referenciado Portes (2000), através do "capital cultural incorporado" e/ou do "capital cultural institucionalizado", o estudante percebe e passa a aceitar o país de destino como ele é e, a partir daí, elabora o seu projeto dentro de um campo de possibilidades, mas circunscrito histórica e culturalmente em termos da sua própria noção de indivíduo e dos temas, prioridades e paradigmas culturais existentes.

\section{Metodologia}

Como referido, este artigo baseia-se em dois projetos de pesquisa: um sobre as motivações dos brasileiros que escolheram o ensino superior português (realizado no âmbito de um doutorado ${ }^{7}$ ) e outro sobre as experiências dos timorenses neste ensino (fruto de um estágio pós-doutoral ${ }^{8}$ ).

Assim, o primeiro projeto, após realizar, entre o segundo semestre de 2014 e o primeiro de 2015, 11 entrevistas às fontes privilegiadas de informações (Diretores e/ou Vice-Diretores das Faculdades e Institutos de Ensino Superior em Portugal que, segundo a DGEEC, mais estudantes brasileiros haviam recebido entre os anos letivos de 2008/2009 e 2011/2012 - último ano com dados disponíveis até então), efetuou a recolha de dados através de dois métodos de análise: (1) Qualitativo - realizou 52 entrevistas em profundidade, entre o segundo semestre de 2014 e primeiro de 2015, aos estudantes brasileiros que estavam no ensino superior português (nas cidades de Coimbra, Lisboa e Porto ${ }^{9}$ ), ou que já haviam estado, mas retornaram ao Brasil (nesse caso alguns estudantes também haviam estado na cidade de Évora); (2) Quantitativo - aplicou um questionário online, que ficou disponível, entre Outubro de 2015 e Janeiro de 2016, a todos os estudantes brasileiros que estivessem em Portugal há pelo mesmo três meses, e cujo principal motivo da migração para este país tivesse sido o estudo. Neste sentido, abarcou estudantes que vieram para a licenciatura, mestrado e doutorado (pleno ou sanduíche). Ainda que não se tenha tratado de uma amostra representativa, obteve 449 questionários válidos, o que representou

\footnotetext{
Realizado do Instituto de Geografia e Ordenamento do Território da Universidade de Lisboa

8 Realizado no Instituto de Ciências Sociais da Universidade de Lisboa.

9 A escolha por esses municípios deu-se porque, de acordo com a DGEEC, foram os que mais receberam estudantes desta nacionalidade até 2012.
} 
$5,2 \%$ do total de estudantes brasileiros que se encontravam no ensino superior português no ano letivo de 2015/2016.

A pesquisa sobre os estudantes timorenses em Portugal foi realizada entre julho de 2017 e março de 2018, mais sistematicamente com 15 estudantes que se encontravam nas universidades de Lisboa, Porto, Évora, Minho, e na Universidade Católica Portuguesa, em níveis de licenciatura, mestrado e doutorado. Além disso, foram efetuados contatos mais superficiais com cerca de 20 outros estudantes em Portugal e mais outros 20 no Brasil, uma vez que esta pesquisa insere-se num projeto mais amplo sobre o acolhimento de estudantes universitários timorenses, que vem sendo desenvolvido, desde 2013, por uma das autoras deste artigo. Deste modo, o trabalho de campo utilizou-se do método etnográfico, compreendendo a observação direta e participante, e entrevistas aos estudantes; para além de contatos com representantes da Embaixada do Timor-Leste em Portugal.

Ambos os projetos utilizaram, ainda, o recurso à pesquisa documental (sites oficiais timorenses, brasileiros e portugueses que tratam do tema) para a obtenção de dados.

\section{O acolhimento de estudantes brasileiros e timorenses em}

\section{Portugal}

As entrevistas realizadas aos estudantes brasileiros e timorenses do ensino superior que foram para Portugal demonstraram que a representação que estes tinham da cultura portuguesa nem sempre correspondeu à realidade. Como estes estudantes apoiaram-se, sobretudo, em informações obtidas pela Internet, o modo como a cultura portuguesa Ihes foi divulgada e/ou como a interpretaram fez com que a construção do imaginário sobre Portugal nem sempre tenha sido condizente com o que encontraram.

Entre os brasileiros inquiridos, 51,7\% considerou o acolhimento em Portugal positivo. Mas enquanto alguns dos entrevistados relacionaram essa positividade com uma questão de "sorte": "Não posso generalizar, também pode ter sido sorte, mas eu acho que, no geral, a recepção que os portugueses fazem aos alunos de fora é muito boa" (aluno de 26 anos, chegou em Portugal em 2012 para fazer o mestrado-pleno), outros disseram que se surpreenderam, positivamente, com a maneira de acolher dos portugueses: "Como Portugal é um país europeu, a gente fica com esse preconceito de que europeu é frio, e eu cheguei morrendo de medo de todo mundo ser super-frio comigo... e português, às vezes, é até mais acolhedor do que brasileiro!" (aluna de 21 anos, chegou em Portugal em 2013 para um intercâmbio na graduação de 5 meses). 
Já em território português, alguns entrevistados brasileiros relacionaram uma forma de acolher "nem positiva, nem negativa", com o "jeito de ser do português": "Eles não vão pegar na sua mão e falar 'vem cá querida que você vai ser acolhida', mas te dão as informações que você precisa" (aluna de 26 anos, esteve em Portugal em 2014 para fazer um ano de doutoradosanduíche).

No entanto, entre os timorenses mais jovens, se acreditava que poderiam ter tido um melhor acolhimento: "Chegamos e não havia ninguém para nos ajudar na hospedagem, nos ensinar como deslocar na cidade, às vezes nem tinha ninguém no aeroporto para nos receber na chegada"10, disse uma aluna de 24 anos, há cerca de cinco anos em Portugal"1. "Se não fossem os parentes ou amigos que já cá estavam, seria muito pior", desabafou um outro aluno de 22 anos, há aproximadamente quatro anos no país.

Alguns dos entrevistados brasileiros e timorenses definiram $\mathrm{O}$ acolhimento em Portugal como, simplesmente, "diferente" do que estavam acostumados em seus países. Três timorenses classificaram os portugueses como "individualistas", sendo "cada um por si".

Ficou, portanto, patente que a ideia de "choque cultural" está presente tanto para os brasileiros, quanto para os timorenses que estão e/ou estiveram em Portugal:

Eu ouvia falar que o brasileiro era extremamente discriminado, que eu iria sofrer um baque muito grande, e quando eu cheguei, não foi assim! Eu acho que é uma questão de comunicação e uma questão cultural... pessoas que já tinham feito esse intercâmbio falavam que os portugueses eram muito diretos, objetivos, e que a gente interpretava muitas vezes como se eles fossem grossos. Mas eu não via desta forma. Eu percebia que era uma questão cultural, ou seja, eles não estão sendo grossos, é outro tipo de relacionamento. (aluno brasileiro, de 23 anos, que esteve em Portugal durante 6 meses para num intercâmbio na graduação).

Como observado por De Haas (2010), se a representação que o migrante tiver do país de destino criar-Ihe expectativas que nem sempre correspondam à realidade, isto poderá ser visto como um ato discriminatório, configurando-se, para além de um problema para a permanência deste no país de destino, na criação de mecanismos de feedback que prejudiquem a continuidade desse sistema migratório.

\footnotetext{
10 Nesta pesquisa, optou-se por não questionar a veracidade do que os aluno relatavam, já que o foco recaiu sobre suas interpretações. No que se refere à recepção em Portugal, uma parte disse que foi recebida por um representante do gabinete da Educação da Embaixada do Timor-Leste ou outros timorenses.

${ }^{11}$ No caso dos depoimentos timorenses, a contagem do tempo foi realizada levando-se em consideração o período entre segundo semestre de 2017 e até março de 2018.
} 
Apesar de no questionário online aos brasileiros apenas 9\% dos respondentes terem apontado "menos discriminação em comparação com outros países" como uma das motivações para a escolha de Portugal, através das entrevistas, muitos disseram que antes de ir já tinham conhecimento de que existia "discriminação de brasileiros em Portugal", assumindo que já haviam criado este imaginário do povo português. Já em Portugal, 67,5\% afirmou que, em algum momento, "sentiu-se discriminado pelo fato de ser brasileiro".

Quanto ao acolhimento prestado pela universidade de destino, 58,6\% dos brasileiros inquiridos considerou-o positivo, "básico" ou "formal": "eu acho que a universidade faz, minimamente, a parte dela. É um acolhimento mínimo, nada demais, mas me deu as direções mínimas pra eu me virar depois" (aluno de 29 anos, que estava em Portugal desde 2013 para um doutorado-pleno). Ainda assim, houve quem o tivesse elogiado: "tem um setor na universidade, pra estudantes de língua portuguesa, que eles foram muito gentis, muito prestativos... me ajudaram muito com a burocracia interna da universidade" (aluna de 37 anos, que veio para Portugal em 2008 para um Mestrado-Pleno). Também os centros acadêmicos das universidades auxiliaram em alguns casos: "o apartamento que a gente ficou foram eles que ajudaram" (aluna de 21 anos que, em 2013, ficou cinco meses em Portugal para fazer um intercâmbio na graduação).

Os depoimentos dos estudantes timorenses em Portugal se coadunam, em geral, com os dos estudantes brasileiros neste mesmo país. Notou-se, entretanto, que os timorenses de pós-graduação que foram para as universidades de Évora e do Porto demonstraram ter sido mais bem-acolhidos e estarem mais adaptados do que os de Lisboa. De fato, ao observarmos os depoimentos dos estudantes brasileiros que vieram (tanto para pós-graduação, quanto para a graduação) os elogios ao acolhimento também incidiram mais sobre as universidades de Évora e Porto, para além de Coimbra.

No caso dos timorenses, uma possível explicação pode estar no fato de alguns professores dessas universidades terem participado em programas de cooperação educacional no Timor-Leste. No caso dos brasileiros, professores e outros representantes de universidades portuguesas também já haviam participado de visitas, formais e/ou informais, às universidades brasileiras. $\mathrm{Na}$ fala de um dos diretores entrevistados:

Nós temos imensas relações com universidades brasileiras, temos muita cooperação, organização de atividades científicas conjuntas, docentes nossos lecionam em muitas universidades no Brasil, e isto dura, sensivelmente, desde 2002. Portanto, são 10, 12 anos de uma cooperação muito intensa, de ir todos os anos, 3 vezes por ano ao Brasil, de manter os acordos todos a funcionar. 
Com tais ações de aproximação, desenvolveu-se uma maior sensibilidade para com o "outro", brasileiro ou timorense, uma vez que muitos desses agentes tiveram a oportunidade de conhecer previamente alguns dos estudantes.

Sobre os estudantes timorenses se sentirem mais acolhidos por universidades como a do Porto e/ou Évora, talvez uma explicação esteja no fato de que, em geral, parte deles nessas cidades compartilham alojamentos, gerando uma maior rede de apoio e conforto emocional frente às adversidades e dificuldades da nova vida. Em Lisboa, ao contrário, entre o grupo analisado, percebeu-se maior dispersão dos estudantes na cidade e em termos de moradia. Já no questionário que foi aplicado aos estudantes brasileiros, enquanto $43,8 \%$ dos que vieram para Lisboa disseram que "viviam sozinhos ou com companheiro, cônjuge, filhos e/ou familiares, em casa alugada" e 24\% que "partilhava casa ou apartamento alugado", dos que estavam no Porto, 40,3\% disse que "partilhava casa ou apartamento alugado", e 25\% que "vivia sozinho ou com companheiro, cônjuge, filhos e/ ou familiares, em casa alugada".

Quanto à Universidade de Évora, na opinião dos estudantes brasileiros entrevistados, para além de terem recebido um bom acolhimento do centro acadêmico desta universidade, um serviço que inicialmente seria para estudantes do Programa Erasmus - o Erasmus Social Network (ESN) - também acolheu esses estudantes através dos chamados "buddies" - alunos que se voluntariavam para mostrar a cidade e auxiliar os novos alunos na procura por alojamento. Assim, explicou um desses estudantes:

No caso de Évora, uma coisa que foi interessantíssimo, e que até já está sendo implantada aqui na universidade de Juiz de Fora, foram os "buddies", que antes mesmo de você chegar na universidade, o departamento de relações internacionais da Universidade de Évora, junto com o ESN, faziam uma lista de pessoas voluntárias da universidade que iriam te ajudar. (aluno de 23 anos, que esteve em um intercambio na graduação, durante seis meses)

Apesar dos Diretores e/ou Vice-Diretores afirmarem não existirem programas de acolhimento específicos para estudantes brasileiros, alguns admitiram possuir um "serviço especificamente para o caso dos brasileiros", ainda que "hoje estes estudantes não precisem de uma estrutura de apoio voltada exclusivamente para eles, pois já 'diluem-se' na faculdade".

Já no caso dos timorenses, a percepção dos estudantes é que existem muito poucos serviços dedicados especificamente a eles: um estudante de doutorado da Universidade do Minho contou que, diante de um atraso no recebimento da bolsa, ficou sem recursos financeiros para pagar o quarto em que morava e as refeições diárias. Foi orientado a procurar o setor de comunicação social, "que divulgou a notícia para toda a gente" (em suas palavras), e só assim conseguiu 
receber apoio da Secretaria de Alimentação e Ação Social da universidade, que "ajuda com albergue, bebida e comida". A falta de divulgação dos serviços de apoio nas universidades foi apontado por uma aluna de 25 anos, há quatro em Portugal, como o principal problema: "às vezes eles existem, mas não sabemos. Um deles, que pouca gente sabe, é o de apoio psicológico da Universidade de Lisboa". Neste aspecto, alguns estudantes brasileiros também concordaram: "Quando eu cheguei lá (Universidade de Coimbra), tinha muita coisa que eu podia ter acionado e não acionei, tinha muita coisa que eu só fui descobrir depois, até uma associação de estudantes, que podia me ajudar na matrícula, eu só fui descobrir depois" (aluna brasileira, de 33 anos, que esteve em Portugal em 2011 para um doutorado-pleno).

$\mathrm{O}$ que as pesquisas parecem indicar é que em grande medida as iniciativas pessoais de professores ou funcionários das universidades em Portugal, sensíveis a esses estudantes internacionais, vêm desempenhando um importante papel em termos de suporte para eles, mas que ainda há um deficit das informações que chegam até esses estudantes. Também pôde ser percebido que as universidades que possuem em seus quadros pessoal que de algum modo tenha participado em programas de cooperação tendem a ter políticas de acolhimento mais efetivas e afetivas voltadas aos alunos estrangeiros.

Contudo, isso não isentou alguns dos estudantes brasileiros entrevistados de perceberem, em alguns professores, atos discriminatórios:

Eu ouvi piada, dentro de sala de aula, de professor, por eu ser brasileira. Eu estava usando um termo da psicologia que é usado no Brasil e o professor disse "fala em português". Eu disse que estava falando e ele disse "não, isso aí é brasileiro, fala português correto". (aluna de 24 anos, que, em 2014, esteve em Portugal durante 5 meses para um intercâmbio na graduação)

Ainda neste aspecto, pelo menos quatro dos estudantes timorenses ouvidos em Portugal também consideraram ter recebido um "tratamento diferenciado" em comparação com os demais colegas. De acordo com um deles, de 21 anos, há dois no país, "eu estava com uma dúvida, havia outros alunos em volta do professor, e para eles [portugueses], o professor estava dando explicações detalhadas, na minha vez, ele disse para eu abrir o livro, conforme havia indicado na aula, e apenas isso".

Não dominar a língua portuguesa, o modo como a mesma é falada e escrita no país de destino, representa para os interlocutores não dominar os estilos de vida e os códigos culturais desse país. Também pode significar não dominar o conteúdo de uma disciplina. Nas palavras de um timorense de 23 anos, há cerca de três anos em Portugal: "o problema da língua em si é grande. Mas eu acabei por aprender mais, lendo dicionário. Minha família 
me estimulou. Mas então tinha o problema dos conteúdos. Essa era uma dificuldade grande. Os termos técnicos também".

Dois timorenses disseram que um dos grandes obstáculos ao aprendizado do Português também estaria no fato de conviverem somente com outros conterrâneos. Como falam em Tétum quase o tempo todo, "isso atrasa o aprendizado", referiu um deles, de 22 anos, há quase três anos no país. Para sanar este problema, outro estudante de 22 anos, há quatro em Portugal e que retornou ao Timor-Leste em 2018, disse que deveria haver um programa de acolhimento, ao menos no primeiro ano, em casas de famílias portuguesas, com articulação entre a Embaixada do Timor-Leste e as universidades, pois essa medida resolveria vários problemas no acolhimento inicial: "os estudantes teriam que falar somente o Português, teria alguém mais responsável zelando pelos alunos mais novos, se aprenderia os hábitos portugueses e sobre o lugar em que se está, como se deslocar, onde ir". Após um ano, segundo este aluno, os estudantes já seriam mais capazes de serem autônomos.

Viu-se, portanto, que a questão do domínio da língua do país de destino e o acolhimento acabam por ser complementares.

Em Portugal, houve relatos de timorenses que foram para alguns institutos portugueses por três meses para aprenderem o idioma, daqueles que passaram por uma formação mínima no Timor-Leste antes da mobilidade acadêmica, além dos que somente começaram a fazer aulas de Português em turmas para estudantes estrangeiros, oferecidas pelas universidades paralelamente ao curso de capacitação profissional.

Outros agentes que apoiam e acolhem esses alunos são as associações de estudantes em Portugal, ainda que não existam em todas as universidades. No caso dos timorenses, por exemplo, no período da pesquisa, Lisboa possuía uma, mas a de Coimbra estava desativada. Formadas exclusivamente por universitários, costumavam atuar de modo coordenado com os gabinetes da Educação das embaixadas timorenses. Assim, eram acionadas para a participação ou organização de festas, comemorações cívicas e eventos esportivos, recepção de alguma autoridade timorense em visita ao país em que estava sediada, mediação entre grupos de alunos e representantes do governo timorense, reuniões da CPLP sobre mobilidade estudantil, entre outras funções observadas. Como também já havia referido um dos estudantes brasileiros entrevistados, o problema das associações é que, muitas vezes, não se têm conhecimento sobre elas.

\section{Discussão dos Resultados}

Dos resultados encontrados nos dois estudos, podemos dizer que as dificuldades observadas no acolhimento praticado em Portugal, tanto para os 
estudantes timorenses como para os brasileiros, relacionam-se, em parte, com o fato desses partirem para o país de destino com um imaginário (muitas vezes baseado na expectativa de que iriam ter uma recepção mais articulada pelas instituições de ensino superior do país de acolhimento), que nem sempre corresponde à realidade encontrada. Por isso, muitos imaginaram uma hospitalidade diferente daquela que encontraram. Enquanto os estudantes timorenses consideraram que o acolhimento poderia ter sido melhor, alguns brasileiros julgaram ter tido "sorte" com o acolhimento em Portugal, ou que este não foi "nem positivo, nem negativo", mas certamente "diferente" do que esperavam ou do que estavam habituados. As diferenças culturais também se podem traduzir num choque cultural vivenciado cotidianamente na instituição e no país de acolhimento.

Ademais, a falta de aceitação da língua portuguesa como é escrita e falada no Brasil também foi apontada pelos estudantes brasileiros como uma falha no acolhimento de Portugal. Já os timorenses, por não dominarem bem o Português, sentiram que as dificuldades na chegada, em circular pela cidade, e para escolher moradia foram, por esse motivo, reforçada - ainda que a língua portuguesa, ao lado do Tétum, também seja um idioma oficial do Timor-Leste.

A falta de informações sobre o funcionamento do sistema acadêmico e problemas nas interações em sala de aula com outros alunos e com professores resultou, muitas vezes, em má compreensão dos conteúdos ministrados nos cursos. A ausência de divulgação dos serviços de apoio disponíveis para eles, também. Além disso, alguns estudantes bolseiros timorenses reclamaram da falta de orientação para os gastos com a bolsa e de ajuda com documentos (vistos, sistema acadêmico, etc.) e os brasileiros referiram que até tiveram alguma assistência, inclusive com o processo de inscrição no curso, mas que só souberam da existência de alguns serviços prestados pela universidade e de associações que os poderiam ter ajudado, quando já estavam em Portugal.

\section{Algumas conclusões e recomendações}

Os resultados de ambas as pesquisas denotam que ainda há muito o que ser feito no que toca ao acolhimento de estudantes internacionais em Portugal. Apesar do aumento na cooperação acadêmica e das relações formais e informais de muitos professores portugueses com Brasil e Timor-Leste, ainda é preciso um maior esforço por parte das instituições de ensino superior no que tange ao conhecimento dos códigos culturais desses estudantes estrangeiros. Isto deve ser inerente ao processo de internacionalização pelo qual estas universidades têm passado.

Em um quadro mais geral, é importante ressaltar que, diferentemente do Brasil que teve a sua independência decretada em 1822, Timor-Leste tem 
passado por um processo de construção de Estado desde 2002, ano em que teve sua independência restaurada.

O processo de formação daquilo que pode ser entendido como uma "identidade nacional", no caso do Timor-Leste envolveu uma combinação de processos baseados na co-existência de instituições sociais relacionadas ao Estado moderno e ao costume. A complexidade disso engloba, também, uma dimensão geracional, em que diferentes gerações foram educadas sob lógicas culturais distintas. Neste sentido, os jovens timorenses possuem um papel significativo no seu país, tendo em vista que a média de idade está em torno dos 18 anos, e que eles detêm ideias particulares sobre a identidade nacional, uma vez que são fluentes em Tétum, familiarizados com a língua indonésia, mas cada vez mais educados em Português (Leach, 2017).

Sendo a língua um fator que compõe a identidade cultural de uma coletividade, enviar estudantes timorenses para os países da CPLP é, portanto, uma estratégia de fortalecimento desse idioma oficial para os atuais e futuros quadros da administração pública do Timor-Leste. O peso dessa responsabilidade, que liga as trajetórias individuais desses estudantes no exterior com os destinos do Estado timorense, tem sido por eles sentido de um modo muito particular. Não sem razão, esses alunos em Portugal reclamaram que as universidades deveriam se preparar melhor para o ensino do Português.

De acordo com os estudantes timorenses que se direcionam para Portugal, eles deveriam ter mais formação nesse idioma antes de seguirem para seus destinos, ou mais tempo de aulas de Português antes de começarem os seus cursos propriamente ditos nas universidades portuguesas. Além disso, conforme sugeriu um aluno, poderia haver um programa de moradia, em que os estudantes fossem abrigados por famílias locais, para melhorarem a língua portuguesa e terem, de algum modo, pessoas mais responsáveis olhando por eles (no caso de alunos de licenciaturas).

No caso dos estudantes brasileiros do ensino superior, estes foram estimulados a investirem em sua formação no exterior devido às políticas governamentais e institucionais de internacionalização, mas atraídos para Portugal devido à partilha do mesmo idioma, e para as universidades portuguesas devido às relações, formais e informais, criadas por professores e pelos acordos de cooperação intra-universitários. Neste sentido, também esperavam que o acolhimento fosse maior do que o encontrado.

A não aceitação da língua portuguesa falada e escrita por esses estudantes, bem como os casos de discriminação sofridos em sala de aula por parte de alguns professores, evidenciou que ainda muito trabalho deverá ser feito para desconstruir a representação de que o português é imune ao 
racismo e possui uma pré-disposição para o convívio com outros povos e culturas (Castello,1998).

Percebeu-se, portanto, que estudantes timorenses e brasileiros reclamaram uma maior atenção e sensibilidade dos professores quanto às suas dificuldades com a língua (que no caso dos brasileiros seria mais diferença do que dificuldade), bem como com os conteúdos ministrados. Afinal, são países cujos sistemas de ensino são diferentes e, por isso, tutoriais sobre o funcionamento destes sistemas seriam bem vistos pelos estudantes recémchegados.

Em ambos os casos, um maior acompanhamento e mais informações por parte das universidades de destino foram reivindicados. Neste sentido, deveria haver uma melhor difusão e ampliação dos serviços que estas prestam aos estudantes estrangeiros.

Conferir maior apoio na chegada e nos momentos iniciais desses alunos no país de destino, conhecer as especificidades das culturas de origem desses estudantes e estar disponível para aprender sobre a melhor forma de recebê-los são estratégias que poderiam ser adotadas pelas universidades portuguesas, de modo que a dádiva da hospitalidade correspondesse a práticas do bem-receber, e que anfitriões e hóspedes pudessem dar, um ao outro, o melhor de si.

\section{Referências}

BINET-MONTANDON, Christiane. Acolhida. Uma construção do vínculo social. In: MONTANDÓN, Alain (dir.). O Livro da Hospitalidade. Acolhida do Estrangeiro na História e nas Culturas. São Paulo: Editora Senac, 2011, p. 1171-1183.

CASTELO, Cláudia. O modo português de estar no mundo: o luso-tropicalismo e a ideologia colonial portuguesa. Porto: Afrontamento, 1998.

DE HAAS, Hein. The Internal Dynamics of Migration Processes: A Theoretical Inquiry. Journal of Ethnic and Migration Studies, v. 36, n. 10, p. 1587-1617, 2010.

DGEEC. Direção Geral de Estatísticas da Educação e Ciência. Disponível em: <http://www.dgeec.mec.pt>

DURAND, Fréderic. Histórias de Timor-Leste. Da pré-história à actualidade. Istória Timor-Leste nian. Husi pre-istoria to'o atualidade. Lisboa: Lidel, 2009.

FAIST, Thomas. The mobility turn: a new paradigm for the social sciences?. Ethnic and Racial Studies, v. 36, n. 11, p. 1637-1646, 2013.

FERREIRA, Suelda de A.; CALLOU, Manuela R. D. A. O processo de construção de Lisboa no imaginário dos imigrantes brasileiros: Fatores explicativos. Revista Rural \& Urbano, v. 1, n. 1, p. 11-18, 2016.

FONSECA, Maria L.; ESTEVES, Alina; IORIO, Juliana. C. Mobilidade internacional de estudantes do ensino superior: os alunos universitários brasileiros em Portugal. In: Vagas Atlânticas - Migrações entre Brasil e Portugal no início do Século XXI, Lisboa: Mundos Sociais, 2015, p. 135-158. 
FONSECA, Maria L.; HORTAS, Maria João. International Students in Portugal. Canadian Diversity, v. 8, n. 5, p. 98-104, 2011.

GÓIS, Pedro; MARQUES, José Carlos. Portugal as a Semi-peripheral Country in the Global Migration System. International Migration Review, v. 47, n. 3, p. 21-50, 2009.

GRASSI, Marie-Claire.Transpor a soleira. In: MONTANDÓN, Alain (dir.). O Livro da Hospitalidade. Acolhida do Estrangeiro na História e nas Culturas. São Paulo: Editora Senac, 2011, p. 45-54.

GUIMARÃES, Felipe Furtado; FINARDI, Kyria Rebeca. Interculturalidade, internacionalização e intercompreensão: qual a relação?. Ilha do Desterro, v. 71, n. 3, p. 15-37, Florianópolis, set/dez 2018. Disponível em: < http://dx.doi. org/10.5007/ 2175-8026.2018v71n3p15>. Acesso em: 01.02.2019.

LEACH, Michael. Nation-Building and National Identity in Timor-Leste. London/ New York: Routledge, 2017.

MARQUES, José Carlos; GÓIS, Pedro. Processos de admissão e de integração de imigrantes altamente qualificados em Portugal e a sua relação com a migração circular. Lisboa: ACIDI, 2014.

MANZI, Joachim; TOUDOIRE-SURLAPIERRE, Frédérique. O desconhecido que bate à minha porta. In: MONTANDÓN, Alain (dir.). O Livro da Hospitalidade. Acolhida do Estrangeiro na História e nas Culturas. São Paulo: Editora Senac, 2011, p. 795-804.

MARTINEZ, Juliana Z. Entre fios, pistas e rastros: os sentidos emaranhados da Internacionalização da Educação Superior. Dissertação (Doutorado em Estudos Linguísticos e Literários em Inglês), Universidade de São Paulo, São Paulo, 2017. MAUSS, Marcel. Sociologie et Anthropologie. Paris: PUF, 1966.

MAZZA, Débora. A internacionalização dos processos formativos - a circulação de pessoas, saberes e práticas no campo das Ciências Humanas. Anais do $32^{\circ}$ Encontro Anual da ANPOCS, GT 25 Migrações Internacionais, 2008, p. 1-30.

MENDES, Nuno Canas. Notas sobre a política externa portuguesa e os interesses portugueses em Timor Leste. In: LEACH, Michael et alii (eds.). New Research on Timor Leste. Proceedings of the 3th. Díli: Timor Leste Association Conference, 2011, p. 125-128.

MONTANDÓN, Alain. Introdução. In: MONTANDÓN, Alain (dir.). O Livro da Hospitalidade. Acolhida do Estrangeiro na História e nas Culturas. São Paulo: Editora Senac, 2011.

NOGUEIRA, Silvia Garcia. Cooperação educacional Brasil-Timor-Leste e a dádiva da hospitalidade paraibana: reflexões sobre uma experiência. In: SANTOS, Mirian; PETRUS, Regina; LOUREIRO, Anita (orgs.). Recortes Interdisciplinares sobre Migrações e Deslocamentos. Rio de Janeiro: Léo Christiano Editorial, 2014.

OIM (Organização Internacional para as Migrações). Glossário sobre Migração, n. 22. Editora Organização Internacional para as Migrações, 2009.

OCDE. Education at a Glance 2013: OECD Indicators. OECD Publishing, 2013. 
PENCHASZADEH, Ana Paula. Hospitalidad, con y sinpapeles. REMHU, Revista Interdisciplinar da Mobilidade Humana, v. 25, n. 50, p. 47-64, 2017.

PEIXOTO, João et alii (eds.). Vagas atlânticas: migrações entre Brasil e Portugal no início do século XXI. Lisboa: Editora Mundos Sociais, 2015, p. 149-175.

PEIXOTO, João et alii (eds.). Regresso ao Futuro - A Nova Emigração e a Sociedade Portuguesa. Lisboa: Gradiva, 2016.

PERROT, Danielle. Dádiva. Hospitalidade e reciprocidade. In: MONTANDÓN, Alain (dir.). O Livro da Hospitalidade. Acolhida do Estrangeiro na História e nas Culturas. São Paulo: Editora Senac, 2011, p. 63-72.

PORTES, Alejandro. Capital social: Origens e aplicações na sociologia contemporânea. Sociologia, Problemas e Praticas, v. 33, p. 133-158, 2000.

RDTL. Timor-Leste. Plano Estratégico de Desenvolvimento 2011-2030. Disponível em: <http://timor-leste.gov.tl/wp-content/uploads/2012/02/Plano-Estrategicode-Desenvolvimento_PT1.pdf>. Acesso em: 02.02.2018.

SALAZAR, Noel. B. The power of imagination in transnational mobilities. Identities: Global Studies in Culture and Power, v. 18, n. 6, p. 576-598, 2011.

SALT, John. International Movements of the Highly Skilled. OECD Social, Employment and Migration Working Papers, 1997, n. 3. OECD Publishing. Disponível: <http://dx.doi.org/10.1787/104411065061>. Acesso em: 22.08.2018.

SOUSA, Isabela Cabral Félix de. Deslocamentos na socialização de estudantes estrangeiros em instituições acadêmicas voltadas para a saúde no Rio de Janeiro. In: PÓVOA NETO, Helion; DE OLIVEIRA SANTOS, Miriam; PETRUS, Regina. Migrações: rumos, tendências e desafios. Rio de Janeiro: Polobooks, 2016, p. 128-145.

SPEARS, Eric. O valor de um intercâmbio: mobilidade estudantil brasileira, bilateralismo \& internacionalização da educação. Revista Eletrônica de Educação, v. 8, n. 1, p. 151-163, 2014.

SILVA, Kelly Cristiane. A cooperação internacional como dádiva. Algumas aproximações. Mana. Estudos de Antropologia Social, v. 14, n. 1, p. 141-171, 2008.

VIDEIRA, Pedro. A mobilidade internacional dos cientistas: construções teóricas e respostas políticas. In: Para um debate sobre Mobilidade e Fuga de Cérebros. Braga: CECS, 2013, p. 138-162.

WATERS, Johanna. L. Geographies of international education: Mobilities and the reproduction of social (dis) advantage. Geography Compass, v. 6, n. 3, p. 123136, 2012. 